\title{
Networking
}

\section{Primary care research networks: perspectives, research interests and training needs of members}

Greta Rait, Stephen Rogers and Paul Wallace Department of Primary Care and Population Sciences, Royal Free and University College Medical School, London, UK

\begin{abstract}
Primary care research networks are considered to be fundamental to the development of a relevant research base in primary care. Networks must be responsive to members' research and training needs in order to evolve. The aims were to gather information about the perspectives, barriers to participation, research interests and training needs of primary care staff interested in participating in the North Central Thames Primary Care Research Network (NoCTeN). A postal questionnaire survey documented training needs and barriers to initiating or developing practice-based research. Focus groups were convened to gain an understanding of needs and explore practical means of addressing these needs. Seventy per cent of practices (57/82) responded to the questionnaire survey. Two focus groups were convened with general practitioners, and one group with practice nurses. Clinical commitments were considered the greatest barrier to research participation. Respondents were keen to participate in research relevant to their practice population. Training was viewed as ideally being project specific and practice based. Mentoring schemes were advocated, together with methods to encourage primary care staff to develop research ideas and access appropriate training. Although there were common themes, there were also differences between general practitioners' and nurses' perceived needs. Investigation of members' perspectives and needs enables networks to respond appropriately and practically. Addressing barriers should encourage members to participate in research and increase primary care-based research activity.
\end{abstract}

\section{Introduction}

Research networks have been in existence in the UK for some time now. A review of European research networks emphasized the importance of networks as vehicles for promoting a research culture in general practice (Fleming, 1988). The Mant report (1997) highlighted the need for 'a sound evidence base derived from high quality R\&D', buying into the idea that primary care research networks are fundamental to achieving this. It is less clear how to build research

\footnotetext{
Address for correspondence: Dr Greta Rait, Department of Primary Care and Population Sciences, Royal Free and University College Medical School, Holborn Union Building, Archway Campus, London N19 5LW, UK.
}

networks, how to generate and sustain enthusiasm among members, and how to match enthusiasm with the capacity to make contributions to high quality outputs.

Literature on network development reveals constraints on the generation of high-quality research, particularly lack of a knowledge base, poor understanding of research methodology and funding problems (Iverson et al., 1988; Nutting, 1996). Although there is some information about the determinants of research participation in primary care (Jowett et al., 2000), a key concern is that little is understood of the perspectives of primary care staff, who comprise the very material of formative primary care research networks.

The North Central Thames Primary Care 
Research Network (NoCTeN) is one of a group of research networks recently funded in the London region through the Culyer mechanism. We describe findings from a questionnaire survey and focus on groups with the earliest recruits. The aims of this study were to provide insights into the perspectives of research-interested primary care staff on research participation, areas of research interest, barriers to different levels of research participation and research training needs. These have been invaluable in guiding the development of our own network and will be relevant to others involved in similar endeavours.

\section{Methods}

\section{Questionnaire survey}

The 'Needs Assessment Questionnaire' (NAQ) was designed within the Department of Primary Care. In order to collect useful information for the network and its future participants, it was discussed with local GPs as well as members of the department during development. Revisions were made in accordance with feedback. It was devised to be brief and easy to complete. The final version had four sections: practice demographics; level of research involvement envisaged and areas of interest; practical barriers to research involvement, training and resource needs; and previous research experience.

A letter introducing NoCTeN was sent to individual GPs $(n=600$; practices $=240)$ in all practices in North Central Thames. One hundred and twenty-four GPs from 82 practices expressed interest and were sent a questionnaire. Practices that did not respond were contacted by letter and telephone. GPs were asked to return one completed questionnaire for their practice. The GP who completed the questionnaire on behalf of the practice was assigned as lead respondent for the practice. Results were analysed on a practice basis.

\section{Focus groups}

Focus groups allow for the study of people's attitudes and experiences. They provide a group interaction to explore views, which are less accessible in one-to-one interviews (Kitzinger, 1996). This methodology was considered appropriate to exploring group perspectives and approaches to the network, barriers to research participation and developing appropriate training and support programmes for research-interested staff.

Focus group participants were sampled from GPs who responded to the questionnaire survey. Two groups were selected to reflect two areas, a specific research interest area, and degree of research involvement envisaged. The third group was selected to reflect the views of practice nurses. This is a large professional group in primary care and was not adequately represented in the questionnaire survey. Sampling of nurses was based on the research-interested practice nurses who were mentioned in the questionnaire. The groups were composed of: individuals interested in a particular area (i.e., primary-secondary interface); individuals interested in being partners in collaborative research; and practice nurses interested in being involved in research.

Participants were invited to PGEA-accredited meetings, each lasting 1. hours. After a short introduction to NoCTeN, the groups were asked to consider four main areas. Two had been identified from key questionnaire findings (barriers to research participation and training needs) and the other two areas were considered to provide information about making the network more accessible to members (Box 1). A facilitator not involved

Box 1 Content of focus groups and minisessions

- Participants' expectations of NoCTeN, and what they thought might be expected of them in return.

- Barriers to participation, both within individuals, within their practices and whether NoCTeN was perceived as accessible.

- Training needs, whether participating in research led by others, or an active collaborator in research

- Views on networking, especially how the various groups within the network might be comprised, how they would work with each other, and with the centre 
with NoCTeN briefly introduced the areas and encouraged the participants to talk to each other. One of the authors (S.R.) made detailed written contextual records of conversations and offered a resumé at the end. The facilitator and S.R. debriefed at the end of the meeting. These comments were recorded and transcribed. The pre-established purpose of the focus group meetings provided the framework for analysis. Comments illustrating particular themes were marked and categorized. Summary results are presented for each of the areas addressed by the focus groups.

\section{Results}

Completed questionnaires were received from 57 of the 82 practices mailed $(70 \%)$. Practices were distributed evenly across the three main Health Authorities covered by the network. They had an average of three whole-time equivalent (WTE) partners (median 3; range 1-8), with list sizes ranging from 1000 to 17000 patients (median range 6001-7000). Practices employed at least one practice nurse and most had access to health visitors $(84 \%)$, district nurses $(81 \%)$, and 'counsellors' (88\%). Most were computerized, with different levels of use and access to software (Table 1). Many practices taught medical undergraduates $(63 \%)$.

\section{Focus group composition}

A sample of 39 GPs were contacted and 10 were able to attend on the dates arranged. Six practice nurses, who were found to be research interested from the questionnaire survey, were invited to attend and four attended the group. Eight of the 10 GPs had outside roles involving research and teaching: a member of the MRC General Practice

Table 1 Practices and information technology: $n=57$

\begin{tabular}{ll}
\hline IT & Percentage of practices \\
\hline Computerized prescribing & 98 \\
Computerized patient records & 88 \\
Practice e-mail & 39 \\
Practice Internet access & 35 \\
Practice Medline & 33 \\
\hline
\end{tabular}

Research Framework, four involved in teaching, two GP tutors and an honorary lecturer with involvement in research network. There were five in each group. Two of the practice nurses were involved with local nurse forums, and two had responsibilities for continuing education.

\section{Research participation}

Survey respondents wanted to be involved in research at different levels. Most were interested in recruiting patients or allowing access for research managed by someone else, with about a third keen on managing their own research (Figure 1).

In the focus group discussions, GPs saw practice development, education and research involvement as inextricably linked. They were interested in projects relevant to their practice and population, rather than producing publications. Research was viewed as a stimulus for education and change. As active participants in research, service staff would provide a 'commitment to putting skills into practice'. The practice nurses recognized how, at another level, research could help identify 'valuable initiatives in care improvement'.

Networking issues were considered crucial; an annual conference and regular newsletter were considered good ways of getting people interested. Networking needed to be supported, with an emphasis on good communication. Participants thought it was important to make use of other networks e.g., primary care groups (PCGs), although nurses expressed concerns about focusing too

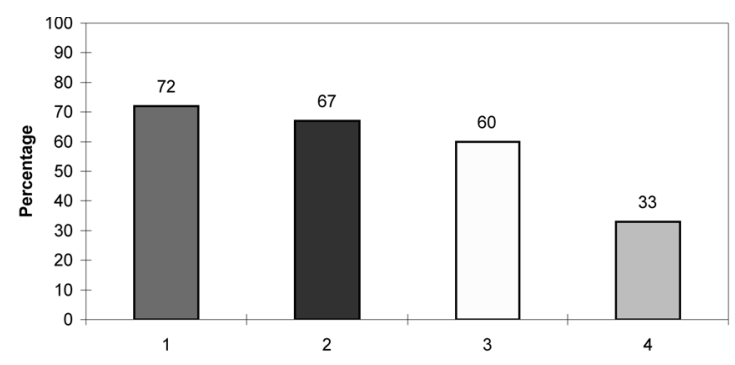

$\underline{\text { Key }}$

3 interested in collaborating on a research project

4 interested in conducting their own projects

Figure 1 Levels of research involvement envisaged: practices 
much on PCGs. In terms of groupings, groups that would be about bringing together people with common research interests or on common research projects, were advocated.

There was a perceived need for a user friendly and accessible support system. It was important to remove the fear of failure and to be patient with new researchers. Participants were less sure how a support system would work. The link with personal and professional development was important. A tiered approach could provide: 'different levels at which we can enter'.

The medico-political and employment situation of practice nurses generated some unique issues. They looked to NoCTeN to support them as they would need confidence to work in a multidisciplinary environment. The nurses wanted to have someone to show them how to use their ideas and: 'break down the hierarchy about what doctors do and what nurses do - outmoded attitudes to tackle'.

\section{Research interests and experience}

Practices had diverse research interests. The most popular areas were 'prescribing' (61\%), 'cardiovascular disease' (58\%) and primary/ secondary care interface $(47 \%)$. About half of practices $(56 \%)$ said they had participated in research at some time (typically someone else's research), but only three practices currently had a staff member with committed research time.

\section{Barriers to participation}

The survey demonstrated that clinical commitments $(83 \%)$ and associated administrative workloads $(65 \%)$ were the greatest barriers to research involvement, closely followed by finding appropriate staff to cover surgeries (63\%). A quarter of practices felt that research was perceived as low priority.

The focus group participants identified pressures of the practice as a barrier. They saw themselves as clinical practitioners first and foremost. Addressing multiple priorities in primary care was a strong theme, with time pressures frequently mentioned. Some felt there would be inevitable conflict with patient care. Although GPs saw the need for protected time, others mentioned that: 'there is a critical level of patient contact below which you cannot go'. Some GPs saw the need for a pool of locums or the input of a regular nonprincipal to cover research sessions. Groups expected protected time for research, but were realistic about resource use and recognised that 'money on its own is not enough - the support system is required to give guidance and stop time wasting'.

Fear of unfamiliar territory was another theme. All groups had ideas, but lacked information on how to take these forward. Everyone wanted opportunities for research training. GP's responses related to skills required to originate and fund research, whereas practice nurses identified skills required to conduct research, such as data collection and IT skills. All wanted to understand the research process better: 'have a team in to discuss needs and help develop research'.

\section{Education and training issues}

A differentiation was made between 'educational needs-based' and 'research needs-based' groups. The first would engage people at the same level in their research careers, the second would focus on common research interests or projects. Linkage of these groups to the centre was envisaged. Questioned on the mechanics of supporting research activity, it was suggested that locality representation would be valuable. This would involve a local primary care professional working in a locality providing support for members and liaising with the NoCTeN office. There was a need for a 'management system in the field - with local groups to inspire them...see the research as having value and application for the practice and population'.

Participants wanted stronger links between primary care, academic departments and secondary care, with opportunities for collaboration, learning and dissemination of research findings. Although it was recognised that support would be targeted at individuals with research ideas and those practices involved in research, there was a plea to support research in a range of practices.

Some respondents had had training in the areas listed in the questionnaire (Table 2). Many indicated the need for training on research methods and conducting research, with a substantial group interested in training on evidence-based medicine.

In the focus groups, a diversity of approaches to delivering education were suggested. Problembased learning and learning 'on the job' were emphasized, although training in methods was recognized as complementary. GPs favoured a col- 
Table 2 Training needs for practices: $n=57$

\begin{tabular}{|c|c|c|c|c|}
\hline Training & $\begin{array}{l}\text { No. needing } \\
\text { training }\end{array}$ & Percent & $\begin{array}{l}\text { No. having had } \\
\text { some training }\end{array}$ & Percent \\
\hline Introduction to primary care research & 34 & 60 & 12 & 21 \\
\hline Funding research & 30 & 53 & 8 & 14 \\
\hline Qualitative methods & 29 & 51 & 13 & 23 \\
\hline Quantitative methods & 26 & 46 & 12 & 21 \\
\hline Evidence-based medicine & 26 & 46 & 14 & 25 \\
\hline Conducting research & 26 & 46 & 7 & 12 \\
\hline Formulating a study & 25 & 44 & 13 & 23 \\
\hline Literature searching & 24 & 42 & 14 & 25 \\
\hline Writing a research proposal & 24 & 42 & 7 & 12 \\
\hline Using E-mail and WWW & 22 & 39 & 14 & 25 \\
\hline Ethical approval & 21 & 37 & 8 & 14 \\
\hline Writing papers & 20 & 35 & 9 & 16 \\
\hline Epidemiology and public health & 18 & 32 & 3 & 6 \\
\hline Presenting and publishing & 17 & 30 & 7 & 12 \\
\hline Critical appraisal & 16 & 28 & 15 & 26 \\
\hline Registering for higher degrees & 14 & 25 & 6 & 11 \\
\hline
\end{tabular}

laborative approach to learning with mentors. Decentralized training was preferred, in particular, visiting tutors, Internet learning and training videos. Travel time and parking made trips to university departments problematic. Nurses were more positive about attending training courses, particularly those accredited for higher degrees. They also recognized the importance of practicebased activities. There was evidence of a general wish for training to be offered to practices as a whole, rather than to individuals. Research training is a 'whole team issue - everyone has training needs, not just doctors and nurses'.

\section{Discussion}

This pragmatic study was designed to gain information early on in the network's development, and to guide the development of a research programme. The study population consisted of those who had been sent information about NoCTeN, and was therefore composed mainly of GPs, with a lesser number of practice nurses. Consequently, the results are not representative of all primary care staff. This was partly addressed by having one focus group exclusively composed of nurses. Different themes from GPs and nurses were demonstrated in this and other studies (Campbell et al., 1999; Greenhalgh and Douglas, 1999). In particular, nurses highlighted the perceived hierarchy in general practice and difficulties crossing professional boundaries. They also felt that their training needs were different to GPs and were more positive about formal training courses.

There were differences between all practices and research-interested practices: research-interested practices had higher numbers of WTE partners and list sizes compared with the region's average. By analysing each practice as a unit in the questionnaire survey, some individual needs and attributes may have been omitted. However, practices were keen to respond as a unit and research is more likely to occur and be sustained with a practice working together (Smith, 1997). The response to the invitation to participate in the focus groups was low, probably due to time pressures. Although focus group participants were deliberately selected, they usually had other roles, and were interested in stimulating research within practices. They were probably not representative of all potential network members but of those who already had some research interest.

It is difficult to assess the degree of transferability of the results, as local factors are important. Some of the key issues of support, networking and training are pertinent to all. A clear picture emerged that practices and individual staff members viewed their research involvement as part of their overall professional development. This 
finding coincides with the results of other work in this area, suggesting that there is considerable potential to develop synergy between clinical work, education and research (Gillam et al., 1999; Wallace et al., 1998; WHO, 1998). Research networks will need to take account of the view that training should be offered to practices as a whole, in order to ensure that training and mentorship are appropriate to support the research practice's overall development needs.

Mentorship schemes can provide protected time and supervision by experienced staff for individual members with research ideas that they want to develop. For example, a scheme could support a member of the research network with a research idea through the development of a research question and through various stages including literature reviews, study design, proposal writing and funding. Funding can be provided to cover sessions for the member to develop research. A scheme would usually be for a defined period and have mutually agreed aims. In a study of Israeli family physicians having a research mentor was associated with research productivity (Giveon et al., 1997). Links with university Departments of Primary Care could provide supervisors and resources ranging from libraries to statistical assistance. Research networks need to encourage larger projects, involved in recruiting via the network, to offer something in return, for example, practice-based training to primary care staff. Research-active practices and staff need support to access appropriate software and training. NoCTeN has begun to implement these ideas.

The findings illustrate a number of barriers to research involvement. Most respondents wanted to limit their involvement, at least initially. Previous work has shown that researchers in primary care find 'hands on' experience with other people's research projects the most effective way of developing their skills (Avery et al., 1996). Our findings suggest that networks should facilitate involvement at the level members consider appropriate. Barriers need to be recognized, especially the need for protected time and appropriate funds. 'Jobbing' GPs in practice are unlikely to commit heavily to academic training unless mechanisms can be found to free them from their clinical commitments. Previously, programmes such as the LIZEI programme (North Thames NHS Executive, 1997) gave GPs protected time to participate in research and training. Early evaluation of the
London Academic Training Scheme for recently qualified GPs has shown that many are keen to continue or have continued with research activities (Smith et al., 1998). Similar schemes exist in the Netherlands (Root and Geus, 1992). This would suggest that the models suggested by respondents, including funding for taught courses and workshops, may prove successful.

The nature of the support provided by networks is likely to be crucial for success. Support has to be both accessible and acceptable. There are a number of recognized models of networking described in the literature (Evans et al., 1997), which are probably effective for different objectives. For example, if the aim is to support grass-roots research activity, a 'crystal' model of network members working together with little hierarchy may be more suitable. If large projects are being supported, then a 'bicycle wheel' model of members linked into a central co-ordinating system may be necessary. The configuration adopted may have an important effect on network productivity. This is currently being evaluated. Our study highlighted nurses' reservations about facilitation being undertaken by a GP. These concerns may apply to other groups, with implications for multi-disciplinary working. Networking issues were given high priority by the respondents, who also highlighted the need for advocacy. Effective research capacity building requires considerable effort and resources to provide a range of mechanisms to encourage networking. Creating databases on members' research interests and training needs may help to access appropriate courses, encourage interest groups, and link them with other parts of the network. Communication within localities and across the network using regular newsletters, interactive websites, and increasingly using electronic mail and support forum, are necessary in developing active networks. Product champions from various professional groups should be involved in networking.

This study of current attitudes towards research among primary care professionals in north London provides indicators of issues likely to affect the successful development of NHS research networks. Although conditions in London differ from those elsewhere, it seems likely that many of the findings will apply generally. 


\section{Acknowledgements}

We are grateful to Marta Buszewicz, for assisting in the development and design of the questionnaire, and Pamela Davenport for facilitating the focus groups.

\section{References}

Avery, A., Wallace, P., Groom, L. and Thomson, A. 1996: Research skills in departments of general practice. European Journal of General Practice 2, 62-4.

Campbell, S., Roland, M., Bentley, E., Dowell, J., Hassall, K., Pooloey, P. et al. 1999: Research capacity in UK primary care. 49, 967-70.

Evans, D., Exworthy, M., Peckham, S. and Robinson, R. 1997: Primary care research networks. Report to the NHS executive South and West research and development directorate. Institute for Health Policy Studies: University of Southampton.

Fleming, D. 1988: The role of research networks in primary care. European Journal of General Practice 4, 96-9.

Gillam, S., Eversley, J., Snell, J. and Wallace, P., editors, 1999: Building bridges: the future of GP education - developing partnerships with the Service. London: Kings Fund.

Giveon, S., Kahan, E. and Kitai, E. 1997: Factors associated with family physicians involvement in research in Israel. Academic Medicine 71, 388-90.

Greenhalgh, T. and Douglas, H. 1999: Experiences of general practitioners and practice nurses of training courses in evidence based health care: a qualitative study. British Journal of General Practice 49, 536-40.
Iverson, D., Calonge, N., Miller, R., Neibauer, L. and Reed, F. 1988: The development and management of a primary care research network 1978-87. Family Medicine 20, 177-81.

Jowett, S., Macleod, J., Wilson, S. and Hobbs, F. 2000: Research in primary care: extent of involvement and perceived determinants among practitioners from one English region. British Journal of General Practice 50, 387-9.

Kitzinger, J. 1996: Introducing focus groups. In May, N. and Pope, C., editors, Qualitative research methods in health care. London: BMJ.

Mant, D. 1997: R\&D in primary care: National working group report. London: Department of Health.

North Thames NHS Executive 1997: London Initiative Zone Educational Incentives Programme annual report 1996-7. London: North Thames NHSE.

Nutting, P. 1996: Practice-based research networks: building the infrastructure of primary care research. Journal of Family Practice 42, 199-203.

Root, J. and Geus, K. 1992: Research training for general practitioners: An experiment in the Netherlands. Family Practice 9, 82-4.

Smith, F., Fuller, J., Hilton, S. and Freeman, G. 1998: The London Academic Training Scheme (LATS): An evaluation. Family Practice 15, S40-S44.

Smith, L. 1997: Research general practices: what, who and why? British Journal of General Practice 47, 83-6.

Wallace, P., Drage, S. and Jackson, N. 1998: Linking education, research and service in general practice. Opportunities for the development of university linked general practices. British Medical Journal 316, 323.

WHO/WONCA 1998: Making medical practice and education more relevant to peoples needs: the contribution of the family doctor.

\section{Networking page submissions}

If you are part of a Primary Health Care Research Network, or if you would like to comment on such networks, you are encouraged to submit a commentary of up to 300-400 words to Dr Karin Friedli at the address below. Longer pieces on other networking topics may also be considered in consultation with the co-ordinator.

Dr Karin Friedli

HertNet Co-ordinator

Faculty of Health and Human Sciences

University of Hertfordshire

College Lane

Hatfield

Herts AL10 9AB

E mail: k.friedli@herts.ac.uk

Tel: 01707284000

Subject to Editorial review 